\title{
Editor's Introduction: Theorizing ICTs and Society
}

\author{
Wolfgang Hofkirchner
}

Institute for Design and Technology Assessment, Vienna University of Technology, wolfgang.hofkirchner@tuwien.ac.at

Given the short period of time internet research and related new fields had to establish themselves, it does not come as a surprise that their development is still a search for identity. Self-reflection is needed when it comes to recommendations for practice, and when it comes to empirical studies, and it is in the domain of theory where the glue can be found that integrates praxis with empirical research.

The four collected papers published here date back to a panel I held on "Approaches towards ICTs and Society - Theories and Methodologies" at the IADIS ICT, Society and Human Beings 2009 (ICT 2009) Conference chaired by Gunilla Bradley.

In the first article, Alice Robbin chooses an empirical approach for investigating different theoretical and methodological approaches researchers are pursuing, while, in the next article, Wolfgang Hofkirchner sketches a logical categorisation. In the third article, Eduard Aibar describes the political consequences of research lines following different theories on the relationship of technology and society. In the last article, Gunilla Bradley provides one example of a theoretical approach that reconciles the society perspective with the individual perspective and gives a normative vision of the good society.

\footnotetext{
About the Author

Wolfgang Hofkirchner

Wolfgang Hofkirchner is Associate Professor at the Vienna University of Technology. Between 2004-2010 he has been University Professor at the Paris-Lodron University of Salzburg. He conducts research in the field of science, technology, and society. In particular, he is interested in the science of information and philosophy of complexity. He has published more than 150 articles and books. He is a founding member of the Unified Theory of Information Research Group and Triple-C.
} 